\title{
SED VOLUIT VINCI VIRIBUS ILLA TAMEN: PRIMERAS APROXIMACIONES AL LEXEMA STUPRUM EN OVIDIO
}

\author{
Sed voluit vinci viribus illa tamen: first approaches to the lexeme stuprum in Ovid
}

\author{
Romina Andrea Flores* \\ Universidad Nacional del Nordeste \\ roandflores@gmail.com
}

Palabras clave
elegía amorosa;
Ovidio; stuprum;
adulterium;
mito

Keywords

love elegy;

Ovid; stuprum;

adulterium;

myth

\section{RESUMEN}

En los textos de la antigüedad clásica encontramos diversos lexemas y sintagmas para aludir a la violencia sexual. En este trabajo, estudiaremos los alcances del lexema stuprum en las obras del poeta romano Publio Ovidio Nasón; término que, aunque resulta infrecuente entre los poetas augusteos, es usado cinco veces en la obra de Ovidio: dos en ars 1.698 (stupro) y 704 (stupri auctorem tui), dos en epist. 9.20 (maculas stupri) y 5.143 (pretium stupri) y una en met. 2.529 (stupri mercede). Dicho lexema, que aludía, originalmente, a una "desgracia", evoluciona para hacer referencia a actos sexuales ilícitos cometidos con mujeres no casadas. En el análisis tendremos en cuenta, en primer lugar, el contexto narrativo en el que se inserta el lexema en cada caso; consideraremos, en particular, las voces enunciativas correspondientes; identificaremos, a continuación, aquellos aspectos semánticos convergentes en torno del lexema y precisaremos, a su vez, las diferencias existentes con respecto a los alcances de otros términos vinculados con stuprum; finalmente, señalaremos las posibles correspondencias del lexema con otros pertenecientes al campo semántico de la violación presente en la retórica ovidiana.

\section{Abstract}

In the texts of Classical Antiquity, we find various lexemes and syntagmas that refer to sexual violence. In this paper, we will discuss the scope of the lexeme stuprum in the works of the Roman poet Publius Ovid Nason; a term which, although uncommon among the Augustan poets, is used five times in Ovid's work: twice in ars 1.698 (stupro) and 704 (pretium stupri), twice in epist. 9.20 (maculas stupri) and 5.143 (pretium stupri), and once in met. 2.529 (stupri mercede). This lexeme, which originally referred to a "disgrace", evolves to refer to sexual assaults committed against unmarried women. In the analysis, we will first take into account the narrative context in which the lexeme is used in each case; we will consider, in particular, the different declarative voices. We will then identify those semantic aspects that converge around the lexeme and in turn, we will specify the existing differences concerning the scope of other terms related to stuprum; finally, we will point out the possible correspondences between the lexeme with others belonging to the semantic field present in the Ovidian rhetoric about rape. 


\section{Introducción}

En la elegía amorosa, tanto latina como griega, son frecuentes las escenas vinculadas con la violencia amorosa: los vestidos rotos, los rasguños y los hematomas están diseminados por los textos (Fredrick, 2002, p. 457). Estas imágenes coinciden con la forma en que tales escritos representan a las mujeres, esto es, como seres indefensos y potencialmente violables, pues su voluntad está siempre coartada por el deseo masculino (Guerra López, 2006, p. 173-174). La imagen de la virgo como cuerpo penetrable no escapa a la obra ovidiana. El análisis de tales episodios revela diversos temas vinculados con la condición femenina, que siguen vigentes y motivan estudios como el presente, orientado a definir la construcción semántica del lexema stuprum a partir del análisis de los distintos episodios ovidianos donde se registra.

Si bien se trata de un término de uso muy esporádico dentro del género, y que resulta difícil definir tanto por su ambigüedad como por su matiz jurídico (Marturano, 2017, p. 4), aparece cinco veces dentro del corpus ovidiano: ${ }^{1}$ dos en ars 1.698 (stupro), 704 (stupri auctorem tui), dos en epist. 9.20 (maculas stupri) y 5.143 (pretium stupri), y una en met. 2.529 (stupri mercede). Este hecho llama nuestra atención y nos invita a llevar a cabo el presente estudio.

Tanto en función de la ambigüedad del término, como de las diferentes perspectivas para explicar sus alcances, resulta necesario aproximarnos filológicamente al lexema stuprum y a otros vinculados con el mismo: adulterium y violatio, en este caso. Esta distinción nos permitirá reconocer las convergencias y particularidades entre dichas nociones, para caracterizar, posteriormente, el uso del stuprum en los casos mencionados.

\section{Conceptos centrales: stuprum, adulterium y violatio}

La palabra stuprum, definida por el OLD en primer lugar como "Dishonour, shame" y, en su segunda acepción, como "Illicit sexual intercourse in any form (whether forced or not) or an instance of it” (Glare, 2012, p. 2020), alude, en materia legal, a la violación de mujeres que no se encuentran casadas; se distingue semánticamente, además, de adulterium (Knox, 1995, p. 167). En tal sentido, si bien parece haber aludido en sus orígenes tan solo a una "desgracia" en términos generales, luego evolucionó para hacer referencia específicamente a distintos actos sexuales ilícitos (Adams, 1982, p. 200), que abarcaban desde el "adulterio" hasta las "violaciones forzadas". ${ }^{2}$ A fin de diferenciar estos conceptos, seguimos la distinción básica sobre las nociones stuprum y adulterium, registradas en el Diccionario de motivos amatorios en la literatura latina: ${ }^{3}$

1. Cf. Knox (1995, p. 167) menciona solo cuatro casos.

2. Cf. Adams (1982, p. 201): "But it came to be specialised (sic) of a sexual disgrace, i.e. an illicit sexual act, whether an adulterous liaison or a forcible violation".

3. En este trabajo seguimos diversas entradas incluidas en el Diccionario de motivos amatorios en la literatura latina, editado por Moreno Soldevila (2011). 
En Roma, cuando una esposa (adultera, moecha) mantenía relaciones sexuales con un hombre que no era su marido (adulter, moechus, corruptor), cometía adulterium. (...) Por su parte, el adulterio cometido por un hombre casado (vir, coniux, maritus) no se consideraba adulterium -a no ser que su pareja fuese una mujer casada (uxor, coniux, mulier, nupta)-, sino que su relación con una mujer soltera respetable -o un hombre- constituía stuprum. (Fernández Sanz, 2011, p. 16)

A la hora de referir la violencia sexual, en cambio, los romanos poseían múltiples expresiones que les permitían diferenciar sus distintas formas; y, en tiempos de Ovidio, los usados con mayor frecuencia eran iniuria, vis y stuprum per vim (Marturano, 2017, p. 4). Domínguez Martín y Martos Fernández definen del siguiente modo la violación (violatio, raptus):

Acceso carnal con alguien en contra de su voluntad o cuando se halla privado de sentido o discernimiento. El violador, en cualquier caso, actúa desde una posición de dominio sobre la víctima, que puede consistir en la superioridad física de un hombre sobre una mujer, un dios sobre una mortal o un poderoso (...) sobre personas de rango inferior. (Domínguez Martín y Martos Fernández, 2011, p. 453)

Al ampliar este concepto y explicar el contexto en el que se enmarcan las violaciones en la literatura latina, la autora señala diversas circunstancias comunes, de las que destacamos aquellas que se encuentran presentes en los textos que analizaremos: la virginidad de las mujeres, que ellas defienden huyendo o luchando; y la fuerza o el engaño de los hombres, que les ofrecen regalos como compensación por haberlas privado de su virginidad. No obstante, puesto que consideramos pertinente añadir a esta suerte de esquema retórico el hecho de que las mujeres siempre son abandonadas después de la relación sexual, privilegiaremos el estudio secuencial de algunos aspectos elaborados a partir del análisis propuesto, para organizar el desarrollo de las relaciones existentes en torno al uso del stuprum en los casos mencionados.

En el análisis revisamos, primero, la inserción del lexema en cada caso y, a continuación, los aspectos desarrollados por Domínguez Martín y Martos Fernández (2011, p. 453-458) en torno a las circunstancias de la violación: la virginidad; la resistencia - el rechazo; la fuerza - el engaño; la recompensa - el embarazo; a los que agregamos: el abandono y la descripción de la violación a partir de la retórica masculina, de la voz enunciativa de la joven ultrajada y de los otros actores que se refieren al hecho, por ejemplo la vox populi.

\section{Contexto narrativo del lexema stuprum en los textos ovidianos}

Las dos referencias correspondientes al Arte de amar se integran en una breve narración sobre el vínculo entre Deidamía y Aquiles, mientras convivían en Esciros, porque Tetis había instado al héroe a disfrazarse de mujer y ocultarse allí para evitar su marcha a la guerra de Troya:

forte erat in thalamo uirgo regalis eodem;

haec illum stupro comperit esse uirum.

uiribus illa quidem uicta est, ita credere oportet: 
sed uoluit uinci uiribus illa tamen.

saepe "mane!" dixit, cum iam properaret Achilles;

fortia nam posita sumpserat arma colo.

uis ubi nunc illa est? quid blanda uoce moraris

auctorem stupri, Deïdamia, tui?

(Ov. ars $1.697-704)^{4}$

Casualmente la virgen real estaba en el tálamo al mismo tiempo;

y, por medio del estupro, ella descubrió que él era un varón.

Ella fue vencida ciertamente por la fuerza, así es conveniente creerlo.

Pero ella, sin embargo, quiso ser vencida por la fuerza.

A menudo “iquédate!" le dijo, cuando Aquiles apresuraba la partida

pues se había puesto las fuertes armas y abandonado la rueca.

¿Dónde está ahora aquella fuerza? ¿Por qué demoras con dulce voz

al autor de tu estupro, Deidamía?

En el caso de Heroidas, son las mismas heroínas quienes escriben cartas en las que relatan, en primera persona, su perspectiva sobre los hechos, lo que les otorga un papel mucho más activo que el que poseían en la tradición anterior (Camino Plaza, 2016, p. 135). En la Heroida 5, por ejemplo, nos hallamos ante un texto en el cual Enone intenta persuadir a Paris para que regrese con ella, después de haber descubierto que ya había llegado de Troya con Helena. En un fragmento de la carta, la ninfa relata la relación sexual no consensuada a la que se ha visto sometida por el dios Apolo, ${ }^{5}$ lo que podemos considerar una innovación ovidiana ya que, si bien la capacidad de curar forma parte del mito de Enone, ninguna otra fuente refiere a Apolo o a la escena de violación como orígenes de este don (Knox, 1995, p. 166). Una de las particularidades de este pasaje reside en el sintagma mediante el que Ovidio caracteriza, a través de Enone, la relación entablada con Apolo: pretium stupri:

\footnotetext{
Me fide conspicuus Troiae munitor amauit;

ille meae spolium uirginitatis habet, id quoque luctando. rupi tamen ungue capillos, oraque sunt digitis aspera facta meis.

nec pretium stupri gemmas aurumque poposci:

turpiter ingenuum munera corpus emunt.

ipse ratus dignam medicas mihi tradidit artes

admisitque meas ad sua dona manus
}

(Ov. epist. 5.139-146) $)^{6}$

4. Las citas latinas de Ov. ars han sido tomadas de la edición crítica de Mozley \& Goold (1979); la autoría de las traducciones castellanas consignadas me pertenece.

5. Pese a la controversia filológica existente en torno a los versos citados, coincidimos con los cuatro argumentos expuestos por Bebergal (2013, p. 119) respecto de su autenticidad.

6. Las citas latinas de Ov. epist. 5 han sido tomadas de la edición crítica de Knox (1995); salvo indicación contraria, la autoría de las traducciones castellanas me pertenece. 
El que levantó las murallas de Troya, conocido por su lira, me amó;

él tiene el despojo de mi virginidad,

esto incluso luchando. Con todo le arranqué los cabellos con las uñas

y su rostro se volvió áspero al tacto por mis dedos.

Pero no reclamé oro ni joyas como pago por el estupro:

los regalos compran vergonzosamente un cuerpo libre.

Él mismo, creyéndome digna, me entregó las artes medicinales

y dejó en mis manos sus dones.

En la carta 9, de Deyanira a Hércules, ${ }^{7}$ también aparece el término stuprum para referir los amores del héroe con Yole, a quien había tomado por esclava y concubina. Deyanira, a diferencia de otras heroínas, se muestra más preocupada por mantener su posición social de esposa de un héroe que de amada abandonada (Blázquez Noya, 2015, p. 15):

quid nisi notitia est misero quaesita pudori,

si maculas stupri facta priora nota? ${ }^{8}$

(Ov. epist. 9.19-20) $)^{9}$

¿Qué buscas sino ser conocido por esta miserable vergüenza

si cedes tus primeras hazañas a las manchas del estupro?

En Metamorfosis, en cambio, la presencia del vocablo surge para describir la situación en la que Júpiter, aprovechando un momento de descuido y soledad de Calisto, comete lo que él mismo llama furtum (Ov. met. 2.423). Como fruto de esa violación, nace Arcas; luego, presa de ira, Juno transforma a Calisto en una osa; para evitar que en una eventual cacería el hijo mate a la madre por error, Júpiter convierte a ambos en las estrellas de dos constelaciones; finalmente, Juno dice:
cur non et pulsa ducit Iunone meoque
conlocat in thalamo socerumque Lycaona sumit?
at uos si laesae tangit contemptus alumnae,
gurgite caeruleo Septem prohibete triones
sideraque in caelo, stupri mercede, recepta
pellite, ne puro tingatur in aequore paelex.

(Ov. met. 2.525-530) $)^{10}$

7. Si bien consideramos importante la inclusión de este caso para la definición del campo semántico propuesto, la obra no ofrece las suficientes descripciones sobre el hecho mismo del stuprum para poder realizar un análisis tan profundo como con el resto de los textos citados. Para ampliar sobre la voz enunciadora de Deyanira, consultar Blázquez Noya (2015).

8. Cf. Blázquez Noya (2015, p. 14), que propone cumulas stupri.

9. Las citas latinas de Ov. epist. 9 han sido tomadas de la edición crítica de Moya del Baño (1986); la autoría de las traducciones castellanas consignadas me pertenece.

10. Las citas latinas de Ov. met. han sido tomadas de la edición crítica de Anderson (1998); la autoría de las traducciones castellanas consignadas nos pertenece. 
¿Y por qué no, repudiada Juno, la hace su esposa y

la lleva a mi lecho y también hace a Licaón su suegro?

Pero si a vosotros conmueve el repudio a su discípula herida

alejad a los Siete Triones de su abismo cerúleo

y echad a las estrellas reunidas en el cielo, premio por el estupro,

para que la concubina no se bañe en ese mar puro.

\section{Tópicos vinculados con el stuprum}

Como hemos mencionado, Domínguez Martín y Martos Fernández (2011, p. 453-458) señalan diversos aspectos comunes al definir el contexto en que se desarrollan las violaciones en la literatura latina. Para el presente análisis, en consecuencia, organizamos la exposición en los siguientes tópicos: la condición virginal de las mujeres víctimas de la violación; la defensa de su integridad física a partir del rechazo o la resistencia a la agresión; los métodos para someter a las mujeres; las estrategias para minimizar los daños; consecuencias de las violaciones; $y$, finalmente, la actitud de los diferentes actores frente al abuso sexual y el abandono.

\section{La condición virginal de las mujeres víctimas de la violación ${ }^{11}$}

Era esta una cualidad muy importante para las mujeres solteras y la sociedad en general, hasta el punto de ser inherente a la condición de "mujer joven" (Martos Fernández, 2011, p. 458). Tanto Enone, como Calisto y Deidamía eran vírgenes antes de padecer stuprum, dato que Ovidio no duda en enfatizar. Referido a Calisto, en Metamorfosis, el término virgo aparece cuatro veces $(2.409,426,427$ y 431). Deidamía es presentada por la voz narrativa como una virgo regalis (ars 1.697 ) y Enone afirma que Apolo quedó en posesión de su spolium virginitatis (epist. 5.140). En función de lo expuesto, tanto la condición de virgo, como la virginitas femenina pueden ser consideradas -respecto de estos tres casos- como condiciones previas al stuprum.

\section{La defensa de la propia integridad física a partir del rechazo o la resistencia a la agresión}

Tanto la resistencia de la joven como el rechazo al agresor señalan las circunstancias no consensuadas en las que tiene lugar el acto sexual. Observamos entonces que las mujeres defienden su virginidad y también se defienden a ellas mismas. Las formas más comunes bajo las que se manifiesta esa resistencia son la huida, el ocultamiento o la metamorfosis. No obstante, pese a que la confrontación del agresor no suele ser frecuente, los textos analizados permiten observar las siguientes excepciones.

11. Para ampliar sobre la cuestión de la virginidad en la etapa augustea, consultar Watson (1983). Sobre sus alcances jurídicos, consultar Caldwell (2015)“. 
La correspondiente a Heroidas resulta, sin dudas, la más emblemática, ya que en Ov. epist. 5.140-141 Enone cuenta cómo se defiende de las intenciones de Apolo, arrancándole los cabellos y arañando su rostro: id quoque lutando rupi tamen ungue capillos, / oraque sunt digitis aspera facta meis. Calisto, que también se enfrenta a un dios -ni más ni menos que a Júpiter-, de todas formas lucha (illa quidem pugnat, Ov. met. 2. 436) y ruega que Juno vea la situación, se compadezca de ella e intervenga, anticipándose a las consecuencias del stuprum (adspiceres utinam, Saturnia, mitior esses, Ov. met. 2.435). Por último, en Ov. ars 1.699 se afirma que Deidamía resulta vencida por la fuerza de Aquiles (uiribus illa quidem uicta est) y, más adelante, el poeta señala que ella también se resistió al acto (uis ubi nunc illa est?, Ov. ars 1.703).

\section{Los métodos para someter a las mujeres}

En el ejercicio de la violencia sexual, los personajes masculinos, divinos y humanos, recurren a diversos métodos. Si bien la fuerza no constituye siempre una condición necesaria, es posible observar ejemplos de dicho comportamiento en los textos seleccionados, como en el ya citado de Ov. ars 1.699, y también en Ov. met.2.434-436 (illa quidem contra, quantum modo femina posset/... sed quem superare puella, / quisve Iovem poterat?), cuando se narra que la joven Calisto rechaza indudablemente la actitud agresiva del dios pero, en contraste, el yo poético se pregunta cómo podría una doncella superar a Júpiter. Otros lexemas a considerar, respecto del mismo pasaje, son el verbo impedo y el sustantivo crimen (impedit amplexu nec se sine crimine prodit, Ov. met. 2.433) debido a que el delito cometido resultará visible sobre el cuerpo desnudo de Calisto, al ser contemplado por sus compañeras de caza (dubitanti vestis adempta est, / qua posita nudo patuit cum corpore crimen, Ov. met. 2.461-462); mientras que Juno sostiene que tanto la iniuria ${ }^{12}$ como el dedecus cometidos por Calisto y Júpiter se dan a conocer por el nacimiento de Arcas (ut fecunda fores fieretque iniuria partu/nota Ionisque mei testatum dedecus esset, Ov. met. 2.472-473).

A su vez, tanto Aquiles como Júpiter engañan a sus víctimas: disfrazados de mujer logran su confianza y se acercan a ellas. El primero, para evitar la guerra, se refugia en la casa del rey Licomedes. Para no ser reconocido, esconde su género (...Achilles/ veste virum longa dissimulatus erat, Ov. ars 1.689-690). Allí, comparte el tálamo con Deidamía y aprovecha la circunstancia para cometer stuprum. Júpiter, por su parte, descubre a Calisto descansando tras una cacería. La ve sola y, para acercarse a ella, toma la forma de Diana, diosa a la que la joven estaba consagrada (protinus induitur faciem cultumque Dianae, Ov. met. 2.425).

Finalmente, la violencia ejercida contra Enone se señala en los versos previamente citados (Ov. epist. 5.140-141). Defenderse, literalmente, con uñas y dientes debería ser más que suficiente señal para Apolo, pero obviamente esto no significa nada para el dios o, simplemente, tener o no el consentimiento de la mujer no le importa.

12. Entendemos por iniuria un daño injusto a una persona libre. A su vez, este puede causar deshonor (dedecus, como en el caso citado) o ser resultado de acciones violentas (cf. Ov.fast. II, 431-433) (Tello Lázaro, 2011, p. 223). 
Podemos comprobar, en consecuencia, que en todos los casos el acto sexual se da por la fuerza, aspecto relevante para distinguir el campo semántico del stuprum del correspondiente al adulterium. Esto se evidencia ante todo en los lexemas vis, crimen, iniuria y dedecus vinculados con actos de violencia sexual (Domínguez Martín y Martos Fernández, 2011, p. 457).

\section{Las estrategias para minimizar los daños. Consecuencias de las violaciones}

Entre las estrategias para minimizar los daños del stuprum, es común en los relatos mitológicos que los agresores ofrezcan retribuciones por el mal causado -como lo sería, obviamente, la violación(Moreno Soldevila, 2011a, p. 356). También se dan casos en los que la virginidad perdida de las mujeres es compensada con alguna dádiva, aunque la "recompensa" más común es la transformación, entendida como una forma de "liberarse" del agravio.

Calisto pasa por dos metamorfosis, ambas como consecuencias del stuprum. La primera, propiciada por Juno, quien, deseosa de venganza, la transforma en osa luego de dar a luz a Arcas, el hijo que concibió con Júpiter. Sin embargo, este acto de sororofobia ${ }^{13}$ no es el que nos compete, sino la transformación que subsigue: tras años de vagar como un animal por el bosque donde una vez cazó junto a sus compañeras, Calisto se encuentra con su hijo, quien también era cazador. Cuando se hallaba listo para atacarla, intercede Júpiter y los convierte en estrellas. Podemos entender este accionar del dios como una recompensa ya que Juno califica su lugar en el cielo como stupri mercede recepta (Ov. met. 2.529).

En cuanto a Enone, su pretium stupri también puede ser considerado una recompensa por la virginidad arrebatada (Domínguez Martín y Martos Fernández, 2011, p. 453). Al parecer, Apolo ofrece gemas y oro, que son rechazados por la ninfa pues la aceptación equivaldría al ejercicio de la prostitución. Por este rechazo el dios la considera digna y le otorga el don de la medicina (nec pretium stupri gemmas aurumque poposci; / turpiter ingenuum munera corpus emunt. / Ipse ratus dignam medicas mibi tradidit artes / admisitque meas ad sua dona manus, Ov. epist. 5.143-146). Otra consecuencia del stuprum es el embarazo. Como ya se expuso, Calisto da a luz a Arcas (causa morae nulla est, et iam puer Arcas (id ipsum / indoluit Iuno) fuerat de paelice natus, Ov. met. 2.468-469).

Observamos en estos casos sintagmas que nos permiten completar el campo semántico del stuprum: stupri mercede recepta y pretium stupri, ambos relacionados con el premio o la recompensa que reciben las mujeres ultrajadas.

13. Sobre el término sororofobia, seguimos a Marturano, quien lo presenta de manera general como "female figures participating in misogyny" (2017, p. 1). 


\section{La actitud masculina frente al abuso sexual. El abandono}

La descripción del amor en términos aplicables al campo semántico de la guerra, común en la poesía elegíaca (Kennedy, 2012, p. 189), se registra con mayor fuerza en los vocablos que presentan el stuprum como una victoria para los hombres. Son numerosas las referencias que encontramos, entre las que nunca falta la noción de vencedor-vencido. En esta posición se ubican Aquiles y Júpiter: el héroe, como ya se expuso, venció por la fuerza a Deidamía; y del dios sabemos que retornó victorioso a los cielos (superum petit aethera victor, Ov. met. 2.437).

En cuanto al abandono, observamos, en los tres casos analizados, que los hombres, una vez realizado el acto sexual, se marchan: Júpiter regresa al Olimpo dejando a Calisto temerosa, incluso de sus compañeras de caza (Ov. met. 2.439-444). Aquiles va a Troya tras ser descubierto (haec illum stupro comperit esse virum, Ov. ars 1.698) y Apolo solo retrasa su partida para ofrecerle su pretium stupri a Enone (Ov. epist. 5.143).

Con este último aspecto podemos cerrar, entonces, el campo semántico del stuprum propuesto por la poética ovidiana.

\section{Presentación del stuprum a partir de las distintas voces implicadas}

Nos resta añadir las otras perspectivas propuestas -que sumamos a las características descriptas por Domínguez Martín y Martos Fernández (2011, p. 453-458) - con respecto al stuprum; esto es, cómo se presenta el hecho para el hombre adúltero, la joven ultrajada y otros actores que se refieren al mismo, por ejemplo, la vox populi.

En cuanto a la voz enunciativa del adúltero, en Metamorfosis Júpiter dice hoc certe furtum coniux mea nesciet (Ov. met. 2.423), donde el lexema furtum se compara a un crimen o flagitium, cuando se refiere al adulterio. Es decir, Júpiter, en una evidente situación de poder, es consciente de que sus actos no son correctos y espera que Juno no se entere de lo sucedido y, si esto ocurre, manifiesta que tampoco le importan las consecuencias (aut si rescierit, sunt, o sun iurgia tanti!, Ov. met. 2.424). En este sentido, el adúltero actúa sin considerar lo correcto de sus actos o lo que estos puedan significar para otros, como su esposa o la mujer con la que tendrá eventualmente el encuentro sexual.

El punto de vista de la joven violada aparece explícitamente en la quinta Heroida cuando Enone justifica el accionar de Apolo, vinculándolo con un acto por amor. La voz enunciativa femenina propuesta por Ovidio, en consecuencia, romantiza el stuprum: me fide conspicuus Troiae munitor amavit (Ov. epist. 5.139).

La perspectiva de la esposa engañada se atestigua en las acciones y palabras de Juno y Deyanira, respectivamente. La primera, como ya hemos expuesto, castiga a Calisto y la transforma en osa por venganza. La segunda, por su lado, desacredita a Yole, pues dice que su aspecto no se corresponde con el de una cautiva (Ov. epist. 9.125-128). 
Finalmente, el narrador de Ars amatoria encarna a todos aquellos que no participan del hecho aunque se permiten hablar de él. Así la vox populi romana inmediatamente después de aseverar que Deidamía estuvo en contra de la relación con Aquiles, se permite dudar sobre los actos de la joven (viribus illa quidem victa est, illa credere oportet, Ov. ars 1.699) y si bien afirma que fue vencida por la fuerza, señala que ella lo quiso así (sed voluit vinci viribus illa tamen, Ov. ars 1.700). El narrador recurre a otro motivo para desacreditar a la mujer al señalar el hecho de que, después del stuprum, pide a su victimario que no la abandone (Saepe 'mane' dixit, cum iam properaret Achilles; / fortia nam posita sumpserat arma colo. / Vis ubi nunc illa ests? Quid blanda voce moraris/ auctorem stupri, Deidamia, tui?, Ov. ars $1.701-704)$.

Las posturas masculinas resultan distantes de la condición femenina en tanto los autores del stuprum no están preocupados por la opinión de los demás ni por las consecuencias de sus actos respecto a ellos mismos o a otras personas. Disfrazados o a través de ardides, engañan a las mujeres y las someten por la fuerza. A su vez, el narrador de Arte de amar, que expresa la cosmovisión romana -y la del autor-, en tanto duda de la veracidad del relato, parece no creer que la mujer haya sido realmente violada y, de esta manera, justifica el accionar del victimario aduciendo que la joven quería ser poseída por su agresor (aunque, previamente, admita que el stuprum fue el medio por el cual la joven descubre el verdadero género del huésped: haec illum stupro comperit esse uirum, Ov. ars 1.698).

La perspectiva femenina propuesta por Ovidio resulta también una justificación del violador: Enone minimiza de alguna manera la violencia del acto, excusando al victimario y vinculando la actitud del dios con la pasión amorosa.

\section{Conclusiones}

Tras lo expuesto, pudimos constatar que, al menos en lo que a la obra ovidiana refiere, el stuprum equivale a un acto de violación. Las condiciones de las mujeres son similares: se trata de vírgenes que buscan defenderse de la violencia masculina, reciben un "premio" tras el hecho (por ejemplo, un don como compensación) o, como resultado de la unión forzada, tienen un hijo; finalmente, son abandonadas. En síntesis, atacadas, cambian irremediablemente y son dejadas a su suerte. Y, por si fuera poco, no reciben compasión de nadie: el hombre las juzga (en el caso del narrador de Ars amatoria), las otras mujeres las ponen en evidencia (como las compañeras de Calisto) o las castigan (como hace Juno, la esposa también ultrajada). Los hombres autores del stuprum, si bien parecen considerar mínimamente las posibles consecuencias de sus actos (en este caso, Júpiter), no atienden a nada más que a su propio deseo sexual; a un costado quedan sus responsabilidades con los huéspedes (como Aquiles) o con la esposa (Júpiter). La fuerza y/o el engaño son los métodos elegidos para alcanzar sus propósitos y, una vez logrados, abandonan a sus víctimas para continuar con sus vidas.

Si bien los autores estudiados establecen que el término stuprum, en su evolución, corresponde tanto a adulterios como a relaciones sexuales forzadas (es decir, equivaliendo tales actos ilícitos) las circunstancias referidas en el análisis permiten confirmar que, en Ovidio, siempre se usa en el contexto de una violación. En este sentido, que se haya podido demostrar que el acto sexual, en cada 
caso, se efectúa por la fuerza resulta relevante para diferenciar el stuprum del adulterium (esto es, la relación sexual consensuada entre una mujer casada y un hombre que no es su marido). Aunque pueden compartir ciertos aspectos, las circunstancias analizadas hacen evidente la distinción entre ambos. En primer lugar, en ningún caso se trata de mujeres casadas, por el contrario, son todas jóvenes vírgenes. En segundo, los actos sexuales son cometidos sin el consentimiento femenino y las víctimas se defienden durante el abuso, como pueden. Finalmente, los hombres están siempre en una posición de superioridad con respecto a las figuras femeninas, de la que se aprovechan para ultrajarlas.

\section{Referencias bibliográficas}

Adams, J. (1990). The Sexual Latin Vocabulary. London, Duckworth.

Anderson, W. (1998). P. Ovidii Nasonis Metamorphoses. Leipzig, Teubner.

Bebergal, C. (2013).A Student's Commentary on Heroides 5, 16, and 17. Florida State University. https:// bit.ly/2QyZ2LG

Blázquez Noya, A. (2015). Las voces de Deyanira en Heroidas IX de Ovidio y Traquinias de Sófocles. Myrtia, 30, 11-33. https://bit.ly/34FVyj6

Caldwell, L. (2015). Protecting virginity. En: Roman Girlhood and the Fashioning of Femininity (pp. 45-78). Cambridge, Cambridge University Press.

Camino Plaza, L. (2016). Las voces femeninas en las Heroidas de Ovidio. Nuevas aproximaciones a la elegía de mujeres. ArtyHum, 20, 2-12. https://bit.ly/31ypWtr

Domínguez Martín, M. y Martos Fernández, J. (2011). Violación. En: Moreno Soldevilla, R. (ed.), Diccionario de motivos amatorios en la literatura latina (siglos III a.C.-II d.C.) (pp. 453-458). España, Universidad de Huelva.

Fernández Sanz, D. (2011). Adulterio. En: Moreno Soldevilla, R. (ed.), Diccionario de motivos amatorios en la literatura latina (siglos III a.C.-II d.C.) (pp. 16-22). España, Universidad de Huelva.

Fredrick, D. (2002). Reading broken skin: violence in Roman elegy. En: Miller, P. (ed.), Latin Erotic Elegy. An anthology and reader (pp. 457-479). London-New York, Routledge.

Fulkerson, L. (2005). The Ovidian Heroine as Author. Cambridge, Cambridge University Press.

Glare, P. (ed.) (2012). Oxford Latin Dictionary. Oxford, Oxford University Press.

Guerra López, S. (2006). Mito y violencia sexuada en las Metamorfosis de Ovidio. En: Molas Font, M. D.; Huntingford Antigas, E.; Guerra López, S. y Zaragoza Gras, J., La violencia de género en la antigüedad (pp. 169-176). Madrid, Instituto de la Mujer. https://bit.ly/3aPe9ds

Jacobson, H. (1974). Ovid's Heroides. New Jersey, Princeton University Press.

Kennedy, D. (2012). Love's Tropes and Figures. En: Gold, B. (ed.), A Companion to Roman love elegy (pp. 189-203). Oxford, Wiley-Blackwell.

Knox, P. (1995). Ovid's Heroides: Select Epistles. Cambridge, Cambridge University Press. 
Martos Fernández, J. (2011). Virginidad. En: Moreno Soldevilla, R. (ed.), Diccionario de motivos amatorios en la literatura latina (siglos III a.C.-II d.C.) (pp.458-460). España, Universidad de Huelva.

Marturano,M.(2017).Vim Parat: Patterns of Sexualized Violence, Victim-Blaming, and Sororophobia in Ovid. CUNY.https://academicworks.cuny.edu/gc_etds/2303

Moreno Soldevilla, R. (ed.) (2011). Diccionario de motivos amatorios en la literatura latina (siglos III a.C.-II d.C.). España, Universidad de Huelva.

Moreno Soldevila, R. (2011a). Recompensa. En: Diccionario de motivos amatorios en la literatura latina (siglos III a.C.-II d.C.) (pp. 356-357). España, Universidad de Huelva.

Moya del Baño, F. (1986). Ovidio. Heroidas. Madrid, Consejo Superior de Investigaciones Científicas.

Mozley,J.y Goold, G. (1979). Ovid in Six Volumes. Vol. 2: Ars Amatoria. Cambridge, Harvard University Press.

Tello Lázaro, J. (2011). Lenguaje técnico jurídico en el amor. En: Diccionario de motivos amatorios en la literatura latina (siglos III a.C.-II d.C.) (pp. 221-225). España, Universidad de Huelva.

Watson, P. (1983). Puella and Virgo. Glotta, 61, 119-143. https://bit.ly/3jml11G

* Romina Andrea Flores es estudiante avanzada de la Licenciatura y del Profesorado en Letras (Universidad Nacional del Nordeste) e integrante del PI 17H014: "Dimensiones monstruosas de la épica y de sus héroes en Heroidas de Ovidio” (Secretaría General de Ciencia y Técnica, UNNE).

RECEPCIÓN: $12 / 06 / 2020$

ACEPTACión: 17/08/2020 